\title{
Comunidades quilombolas acumulam conquistas, mas não é tempo de baixar a guarda
}

Quilombo communities accumulate achievements, but it is no time to lower the guard

Oriel Rodrigues de Moraes ${ }^{1}$

Rosa Peralta ${ }^{2}$

Resumo: Em fevereiro de 2018, o Supremo Tribunal Federal (STF) validou a constitucionalidade do Decreto 4.887/2003, sem o qual o já tortuoso processo de titulação das terras quilombolas se tornaria praticamente inviável. A partir de textos acadêmicos, jornalísticos, jurídicos e institucionais, analisamos o limite dessa conquista, já que os entraves ao direito quilombola permanecem e até mesmo se acirram. Abordaremos também a mobilização e a construção de alianças do movimento quilombola em meio a um cenário político cada vez mais adverso. Consideramos, por fim, que um olhar mais detido sobre todos os atores incidentes na "paisagem quilombola" nos permite constatar

1 Oriel Rodrigues de Moraes é Bacharel em Direito pela Pontifícia Universidade Católica do Paraná (PUCPR), advogado, mestrando em Meio Ambiente e Desenvolvimento (MADE) na Universidade Federal do Paraná. Moraes é também pesquisador em direitos de povos e comunidades tradicionais, facilitador em processos gerenciais na formação de agentes multiplicadores em gestão de associações de quilombos. Agente de etnodesenvolvimento em assuntos relacionados à economia solidária. Membro da Conaq e morador do quilombo de Ivaporunduva (SP).

2 Rosa Peralta tem graduação em Comunicação Social pela UFRJ (1999), Mestrado pelo Programa de Pós-Graduação em Desenvolvimento e Meio Ambiente (Prodema) da UFPB (2012) e atua junto à questão quilombola desde 2005. 
que estamos diante de um conflito socioambiental por excelência, em que a apropriação das terras e seus recursos está em jogo.

Palavras-chave: comunidades quilombolas, conflitos socioambientais, justiça socioambiental

Abstract: In February 2018, the Federal Supreme Court validated the constitutionality of Decree 4.887 / 2003, without which the already tortuous process of titling quilombo lands would become virtually unattainable. By using academic, journalistic, juridical and institutional texts as sources, we analyze the limit of this conquest, since the obstacles to the effectiveness of quilombo land rights remain and even increase. We will also address the mobilization and building of alliances of the quilombo movement amidst an increasingly adverse political scenario. Lastly, we consider that a closer look at all the actors involved in the "quilombo landscape" allows us to verify that we are facing a socio-environmental conflict par excellence, in which the appropriation of land and its resources is at stake.

Keywords: quilombo communities, socioenvironmental conflicts, socioenvironmental justice

\section{INTRODUÇÃO}

Em fevereiro de 2018, os quilombolas conseguiram uma façanha: por 10 votos a 1, o Supremo Tribunal Federal (STF) decidiu pela improcedência da Ação Direta de Inconstitucionalidade (ADI) 3.239/2004 que buscava impugnar o Decreto 4.887/2003, que regulamenta o procedimento para identificação, reconhecimento, delimitação, demarcação e titulação das terras ocupadas por remanescentes das comunidades dos quilombos. Chamamos de façanha tal decisão ao considerarmos as cotas de poder dos atores envolvidos, assim como o panorama político no país naquele momento (logo após o golpe que levou ao impeachement da Presidenta Dilma Rousseff), marcado por inúmeros retrocessos em relação à garantia de direitos básicos da população 
brasileira, muitas vezes com a omissão, anuência ou participação direta da Suprema Corte ${ }^{3}$.

O presente artigo inicia buscando analisar o que significou essa vitória no âmbito do judiciário, elencando de que forma os argumentos apresentados pela ADI 3.239/2004 foram rejeitados pelos(as) ministros(as) do STF. A análise desse episódio de vitória para a causa quilombola também passa por inventariar os principais atores e setores envolvidos, inclusive os de natureza "fantasmagórica", aqueles que, mesmo não estando presentes fisicamente no(s) sítio(s) de conflito, exercem uma influência sobre ele (LITTLE, 2006), notadamente no caso da mídia hegemônica.

Um olhar mais detido sobre os atores envolvidos, seus argumentos e articulações políticas, nos permite perceber que estamos diante de um conflito socioambiental por excelência, já que o que está em jogo é a apropriação das terras e seus recursos incidentes, características dessa "nova frente de expansão de fronteiras" (LITTLE, 2002).

Acreditamos ser importante identificar também quais são os entraves que permanecem no âmbito dos processos administrativos e de destinação de recursos financeiros com vistas à regularização fundiária desses territórios. Atualmente, segundo estimativas da Coordenação Nacional de Articulação de Comunidades Negras Rurais Quilombolas (Conaq), existem mais de seis mil comunidades remanescentes de quilombo em todo o território brasileiro, mas apenas 175 terras foram tituladas desde a introdução do Artigo 68 na Constituição Federal de 1988 (CPI-SP, 2018). Ainda que durante a gestão da Presidenta Dilma Rousseff o contexto não fosse favorável às demandas quilombolas, após o golpe que a destituiu em 2016, houve um recrudescimento

3 Consideramos importante destacar que o presente artigo foi elaborado e apresentado à publicação no período anterior à chegado ao poder do atual presidente Jair Bolsonaro. Desde que Bolsonaro assumiu a presidência, houve várias e importantes mudanças nos procedimentos administrativos de regularização fundiária dos territórios quilombolas e nas demais políticas de atendimento a esses grupos. Embora apontem para um cenário inequivocamente mais hostil à comunidades quilombolas, tais mudanças não serão aqui abordadas. 
de ações contrárias e outros retrocessos que atingiram tanto direta quanto indiretamente o povo quilombola.

Para além da vitória no STF, abordaremos também que iniciativas de mobilização e construção de alianças do movimento quilombola têm se traduzido em conquistas importantes, como a titulação de várias terras em todo o país, ainda que algumas delas ainda enfrentem pressão para aceitarem reduzir suas demandas territoriais. A ideia é apontarmos os avanços e perspectivas de luta e, dessa forma, fecharmos a análise do contexto quilombola pós julgamento do STF.

\section{FIM DA BATALHA NO STF: QUEM, QUANDO, COMO E POR QUE}

Os argumentos levantados pelo Autor na devida Ação Direta de Inconstitucionalidade, o Partido Democratas (DEM), antigo Partido da Frente Liberal (PFL), derivam do inconformismo relacionado ao tratamento dado às terras quilombolas no refere ao disposto na Constituição de 1988 pelo artigo 68 do Ato das Disposições Constitucionais Transitórias (ADCT), que garante o direito à propriedade das terras que ocupam.

A ADI 3.239/2004 alegava primeiramente que o Decreto 4.887/2003 estaria ferindo o princípio de "reserva legal", já que a matéria teria que ser regulamentada em lei, e não via decreto do poder executivo, olvidando assim das garantias de norma supralegal, no caso, a Convenção 169 da Organização Internacional do Trabalho (OIT) sobre Povos Indígenas e Tribais, que foi aprovada pelo Decreto Legislativo 143/2002 e ratificada pelo Decreto 5.051/2004.

Também foi questionado o dispositivo de desapropriação de propriedades de terceiros por interesse social, alegando que feria o direito à propriedade, o que foi rechaçado pela Ministra Rosa Weber. Segundo o voto da Ministra, a interpretação do artigo 68 do ADCT:

... passa, pois, pela perspectiva de sua íntima relação com o disposto nos arts. 215 e 216 do corpo da Constituição da República. Nessa medida, a compreensão sistemática da Carta Política 
não só autoriza como exige, quando incidente título de propriedade particular legítimo sobre as terras ocupadas por quilombolas, seja o processo de transferência da propriedade para estes mediada por regular procedimento de desapropriação. E esse imperativo constitucional é preservado pelo art. 13 do Decreto 4.887/2003. (BRASIL, 2018, p.51).

O Ministro Fachin também se posicionou sobre o tema. Em seu voto, não desconsiderou a eventualidade de conflitos fundiários, mas observa que, ao prever a desapropriação, o Decreto não ignora a propriedade existente, que terá inclusive direito a uma justa indenização.

A decisão do STF de validar a constitucionalidade do Decreto $4.887 / 2003$ se baseou no reconhecimento do acesso à terra para quilombolas como direito humano, como instrumento de combate ao racismo, além de ter afastado a possibilidade de aplicação do marco temporal para titulação de territórios quilombolas (PRIOSTE, 2018), o que era fonte de grande preocupação por parte do movimento não apenas quilombola, como indígena.

Apenas os Ministros Dias Toffoli e Gilmar Mendes votaram pela aplicação dessa tese, que estabelece que só teriam direito às terras as comunidades que tinham sua posse em 5 de outubro de 1988. O Ministro Ricardo Lewandowski afirmou que a proposta de marco temporal apresentada pelo Ministro Dias Toffoli impunha às comunidades quilombolas a obrigação de produzir uma "prova diabólica", impossível de ser obtida na prática. Obrigar as comunidades a provar que foram expulsas da terra de forma violenta seria, na verdade, impedir o exercício do direito e desconsiderar a notória opressão histórica a que as comunidades quilombolas estão submetidas. (PRIOSTE, 2018)

Entretanto, foi o critério de autoatribuição da identidade quilombola que figurou como principal alvo da ADI 3.239/2004. Alegava-se que a aparente flexibilidade de tal critério suscitaria a ação de oportunistas para obterem acesso indevido a terras. No entanto, tanto o Decreto $4.887 / 2003$ como as demais normas de reconhecimento, delimitação e titulação de territórios quilombolas estão longe de serem flexíveis, 
impondo, aliás, inúmeras etapas ao reconhecimento e efetivação do direito quilombola, como veremos com mais detalhes adiante. Sobre esse ponto, vejamos o voto do Ministro Barroso:

Penso que o decreto é perfeitamente válido do ponto de vista formal. Também penso que o critério de autodefinição igualmente impugnado é perfeitamente válido. Aqui, como em qualquer outra situação da vida, a autodeclaração, ou autodefinição, não é uma carta branca para a fraude, portanto, mesmo nas questões raciais, nós aqui assentamos que a condição racial de cada um se faz por autodeclaração, mas se, evidentemente, houver fraude, é possível, por formas legítimas, desfazer-se a fraude. Aqui, no caso da autodefinição, é preciso registrar que a autodefinição feita pela comunidade quilombola é apenas o ponto de partida de um procedimento - eu contei - que é feito em 14 fases, que inclui laudo antropológico, inclui manifestação do INCRA e inclui manifestação de todos os interessados. Logo, eu acho que é perfeitamente possível expurgar-se uma fraude que eventualmente pudesse ocorrer, que, aliás, era um dos outros argumentos, a possibilidade de fraude. A ideia de que pudesse haver fraude é um pouco fantasiosa, porque era preciso enganar muita gente! E era preciso que a Comunidade Quilombola conseguisse criar uma sociedade puramente imaginária para se argumentar que há fraude. Ela teria que documentar um modo de produção econômica, as relações com os antepassados, teria que simular os cemitérios que geralmente se encontram nessas comunidades. Então, eu penso que a possibilidade de fraude envolveria muitos erros ou muitos conluios para que pudesse ocorrer. De modo que eu também descarto esse terceiro fundamento. (BRASIL, 2018, p. 219-220)

Mas o que também não devemos esquecer é que a relação entre os indivíduos de uma comunidade quilombola e a sua terra não se enquadra no paradigma clássico do direito civil, baseado no direito de propriedade privada. São necessárias "novas" categorias de pensamento para uma compreensão que se aproxime minimamente do que a terra significa e representa para as comunidades quilombolas. Na grande maioria dos casos, as terras não são objeto de apropriação privada e 
de uso exclusivo, ao contrário, são de posse e uso coletivo, pois não há glebas de domínio privado, apenas áreas destinadas à produção familiar, ou áreas essencialmente comuns. Nesse sentido, é de se ressaltar a maneira como os quilombolas concebem as suas terras, que geralmente são um espaço de vida e bem viver pensando nas presentes e futuras gerações, marcando assim um território de vida. Assim, quando o Estado titula uma terra quilombola e ou demarca uma terra indígena, essas terras saem do mercado e não voltam mais. Essa é, portanto, a grande questão da não titulação das terras quilombolas e da demarcação das terras indígenas.

Além dos argumentos contrários ao Decreto 4.887/2003 apresentados pela ADI 3.239/2004, acreditamos ser bastante significativo e ilustrativo para a conjuntura quilombola enumerar quais são as partes inscritas no processo na figura de amici curiae (ver Tabela 1) e os setores que representam. Das 25 instituições/organizações "amigas da corte" que se propuseram a fornecer dados e aspectos de relevância para instruir os votos dos(as) Ministros(as) do STF, nota-se que apenas cinco se colocavam como contrárias à manutenção do referido Decreto. Apesar de seu número reduzido, representam setores que historicamente detêm grande capital político e econômico, a saber: a Sociedade Brasileira Rural, a Confederação Nacional da Agricultura e Pecuária do Brasil (CNA), a Associação Brasileira de Celulose e Papel (Bracelpa), a Confederação Nacional da Indústria (CNI) e o estado de Santa Catarina, de onde vem ninguém menos que Deputado Federal Valdir Collato (PMDB/SC), autor do Projeto de Decreto Legislativo n. $44 / 2007$, que propõe a sustação do Decreto $4.887 / 2003$ e de todos os processos administrativos vinculados a ele, o que anularia os poucos títulos emitidos com base no marco legal vigente. Para termos uma ideia de qual é o lugar de fala do deputado, em junho de 2007, em plenário na Câmara dos Deputados de Santa Catarina, Collato lançou o Movimento dos Com Terra (MCT). 
Tabela 1. Lista dos amici curiae, divididos entre favoráveis ou contrários à constitucionalidade do Decreto 4887/2003

\begin{tabular}{|c|c|}
\hline $\begin{array}{l}\text { Favoráveis à constitucionalidade do } \\
\text { Decreto }\end{array}$ & $\begin{array}{l}\text { Contrários à constitucionalidade } \\
\text { do Decreto }\end{array}$ \\
\hline Instituto Pro Bono & Estado de Santa Catarina \\
\hline Conectas Direitos Humanos & $\begin{array}{c}\text { Confederação Nacional da Agricultura } \\
\text { e Pecuária do Brasil - CNA }\end{array}$ \\
\hline $\begin{array}{l}\text { Sociedade Brasileira de } \\
\text { Direito Público - SBDP }\end{array}$ & Confederação Nacional da Indústria \\
\hline $\begin{array}{l}\text { Centro Pelo Direito à Moradia } \\
\text { Contra Despejos - Cohre }\end{array}$ & $\begin{array}{l}\text { Associação Brasileira de Celulose } \\
\text { e Papel - Bracelpa }\end{array}$ \\
\hline Centro de Justiça Global & Sociedade Rural Brasileira \\
\hline \multicolumn{2}{|l|}{ Instituto Socioambiental - Isa } \\
\hline \multicolumn{2}{|l|}{$\begin{array}{c}\text { Instituto de Estudos, Formação e } \\
\text { Assessoria em Políticas Sociais - Polis }\end{array}$} \\
\hline \multicolumn{2}{|l|}{ Terra de Direitos } \\
\hline \multicolumn{2}{|l|}{$\begin{array}{c}\text { Federação dos Trabalhadores } \\
\text { na Agricultura do Estado do } \\
\text { Pará - Fetagripara }\end{array}$} \\
\hline \multicolumn{2}{|l|}{ Estado do Pará } \\
\hline \multicolumn{2}{|l|}{$\begin{array}{l}\text { Centro de Assessoria Jurídica } \\
\text { Popular Mariana Criola }\end{array}$} \\
\hline \multicolumn{2}{|l|}{$\begin{array}{l}\text { Koinonia Presença } \\
\text { Ecumênica e Serviço }\end{array}$} \\
\hline \multicolumn{2}{|l|}{$\begin{array}{l}\text { Associação dos Quilombos } \\
\text { Unidos do Barro Preto e Indaiá }\end{array}$} \\
\hline \multicolumn{2}{|l|}{$\begin{array}{l}\text { Associação de Moradores Quilombolas } \\
\text { de Santana - Quilombo de Santana }\end{array}$} \\
\hline \multicolumn{2}{|l|}{$\begin{array}{c}\text { Coordenação das Comunidades } \\
\text { Negras Rurais Quilombolas } \\
\text { de Mato Grosso Do Sul }\end{array}$} \\
\hline \multicolumn{2}{|l|}{$\begin{array}{l}\text { Instituto Nacional de Colonização } \\
\text { e Reforma Agrária - Incra }\end{array}$} \\
\hline \multicolumn{2}{|l|}{ Estado do Paraná } \\
\hline \multicolumn{2}{|l|}{$\begin{array}{l}\text { Conferência Nacional dos } \\
\text { Bispos do Brasil - CNBB }\end{array}$} \\
\hline \multicolumn{2}{|l|}{$\begin{array}{l}\text { Instituto de Advocacia Racial } \\
\text { e Ambiental - lara }\end{array}$} \\
\hline $\begin{array}{c}\text { Clube Palmares de } \\
\text { Volta Redonda - CPVR }\end{array}$ & \\
\hline
\end{tabular}

Fonte: BRASIL, 2018 
A Confederação Nacional da Indústria (CNI), por sua vez, apresentou um pedido de mais de 100 páginas para adentrar no processo como amicus curiae. No documento, a CNI aludiu aos argumentos "bem fundamentados" apresentados pelo Estado de Santa Catarina. A fim de justificar sua legitimidade para figurar como amicus curiae, alegava "a repercussão do Decreto 4.887/2003 sobre propriedades de diversas indústrias representadas pela $\mathrm{CNI}$." A maioria das peças anexadas no pedido, no entanto, faziam referência ao "impacto" do decreto especificamente sobre indústrias de papel e celulose, notadamente Aracruz Celulose e Suzano Papel e Celulose, no Estado do Espírito Santo (ver Tabela 2), anexando ainda diversos documentos oficiais trocados entre o Incra e o Gabinete de Segurança Institucional (GSI) sobre o processo de reconhecimento e delimitação das comunidades quilombolas de Linharinho, Angelim e São Jorge, no Espírito Santo. Importante ainda ressaltar que o conflito envolvendo as comunidades do Espírito Santo e as empresas do setor de papel e celulose - atividade industrial que ficou conhecida por promover um "Deserto Verde" naquela região - tornou-se um dos casos mais emblemáticos do país, em função da violência a que essas comunidades foram submetidas por parte dessas empresas, que encontraram amparo no âmbito jurídico, policial, midiático e de setores do governo Federal, como do GSI (KOINONIA, 2005).

Tabela 2. Áreas "atingidas" por comunidades quilombolas

\begin{tabular}{|c|c|c|c|}
\hline \multicolumn{3}{|c|}{ REIVINDICAÇÕES COMUNIDADES QUILOMBOLAS } \\
\hline PROPRIETÁRIO & \multicolumn{3}{|c|}{ COMUNIDADES } \\
\hline & LINHARINHO & ANGELIM & SÃO JORGE \\
\hline ARACRUZ & $8.455,52$ ha & $7.529,10$ ha & $8.631,47$ ha \\
\hline SUZANO & 305,95 ha & $1.022,60$ ha & 212,29 ha \\
\hline ARACRUZ (CONSÓRCIO) & - & - & - \\
\hline SUZANO (CONSÓRCIO) & 14,37 ha & 362,44 ha & 98,30 ha \\
\hline PRODUTOR FLORESTAL (ARCEL) & 31,56 ha & - & 193,75 ha \\
\hline TERCEIROS & 753,36 ha & $4.817,57$ ha & $3.930,95$ ha \\
\hline TOTAL REIVINDICADO & $9.560,76$ ha & $13.731,71$ ha & $13.066,76$ ha \\
\hline
\end{tabular}

Fonte: BRASIL, 2018. 
Não bastasse a ênfase da CNI acera da incidência de comunidades quilombolas capixabas sobre atividades das empresas de papel e celulose, a Bracelpa também entrou com pedido para integrar o rol de amici curiae. No pedido, informava que as 37 empresas associadas à Bracelpa detêm 1,7 milhão de hectares de florestas plantadas para a produção de papel e celulose, espalhados em 14 estados, e 2,6 milhões de hectares de áreas de preservação permanente e reserva legal (BRASIL, 2018). As demais instituições que defendiam a impugnação do Decreto não revelaram dados tão precisos, embora haja de se convir que a Sociedade Brasileira Rural e a Confederação Nacional da Agricultura e Pecuária do Brasil (CNA) dispensam maiores explicações acerca do seu interesse na causa. Ao considerarmos o Censo Agropecuário de 2006, por exemplo, podemos facilmente deduzir que essas organizações representam o segmento agropecuário detentor de nada menos que cerca de $75 \%$ da área agrícola do país ${ }^{4}$. Afinal, segundo o Censo de 2006, o segmento da agricultura familiar ocupa menos de $25 \%$ da área, embora constitua cerca de $85 \%$ dos estabelecimentos agrícolas do país. Utilizamos aqui os dados de 2006 pelo fato de que Censo Agropecuário de 2016 ter simplesmente suprimido essa informação sobre a área ocupada pela agricultura familiar e o agronegócio ${ }^{5}$, o que contribui para invisibilizar não apenas o grau de concentração de terras no país, como também a capacidade de resiliência da agricultura familiar que, mesmo ocupando $1 / 4$ das áreas agrícolas, emprega quase $70 \%$ da mão de obra no campo e é responsável pela maior parte da produção dos principais gêneros alimentícios das famílias brasileiras (GUIMARÃES, 2017).

4 Censo Agropecuário 2006. Disponível em:<https://biblioteca.ibge.gov.br/visualizacao/ periodicos/50/agro_2006_agricultura_familiar.pdf $>$.

5 Em reportagem publicada pela Escola Politécnica de Saúde Joaquim Venâncio (unidade técnico-científica da Fiocruz), o pesquisador Paulo Alentejano da Universidade do Estado do Rio de janeiro (UERJ) critica a redução dos questionários do Censo de 2016, o que tornaria impossível diferenciar os empreendimentos agropecuários que são ou não familiares. Segundo Alentejano, "Estamos vivendo uma hegemonia tão grande do agronegócio que não se quer mais nem identificar a existência da agricultura familiar como algo importante no Brasil”. (GUIMARÃES, 2017). 
Como nos descreve Almeida (2005), não é difícil imaginar o temor que as demandas territoriais quilombolas provocam nesses atores, que não costumam medir esforços para perpetuar e, por que não, acentuar o quadro de concentração de terras no Brasil.

O fato de a propriedade não ser necessariamente individualizada e aparecer sempre condicionada ao controle de associações comunitárias torna-a um obstáculo às tentativas de transações comerciais e praticamente as imobiliza enquanto mercadoria. As terras das comunidades quilombolas cumprem sua função social essencial quando o grupo étnico, manifesto pelo poder da organização comunitária, gerencia os recursos no sentido de sua reprodução física e cultural, recusando-se a dispô-los às transações comerciais. (...) Contraria, portanto, as agências imobiliárias de comercialização, vinculadas a bancos e entidades financeiras, do mesmo modo que contraria os interesses latifundiários, os especuladores, os 'grileiros' e os que detêm o monopólio dos recursos naturais. (ALMEIDA, 2005, p. 6-7)

\section{A MÍDIA ANTIQUILOMBOLA}

Entretanto, essa informação sobre a importância da agricultura familiar (categoria à qual pertence a maior parte das comunidades quilombolas) não foi suprimida apenas do Censo Agropecuário, mas também vem sendo sistematicamente ignorada por outro ator que desempenhou um papel relevante nessa arena de conflito: a grande mídia. A Rede Globo, aliás, não esconde sua preferência pelo setor do agronegócio e chegou mesmo a lançar em 2016 uma campanha custeada com recursos próprios intitulada "O Agro é Tech. O Agro é Pop. O Agro é Tudo."

Para além da propaganda explícita do agronegócio, desde 2005, alternando períodos de ataques mais "sistemáticos" e outros "episódicos", veículos como a TV Globo, o Jornal O Globo, O Estado de São Paulo, a Folha de São Paulo e a Revista Veja, para citar os de maior alcance, empreenderam uma campanha em franca oposição ao direito quilombola. 
Em 2007, a campanha antiquilombola se tornou mais ostensiva, ocupando inclusive horários nobres da televisão ${ }^{6}$. Em pleno Jornal Nacional, a Rede Globo exibiu reportagens questionando a autenticidade da identidade quilombola da comunidade de São Francisco do Paraguaçu (BA). O Jornal O Globo e o Estado de São Paulo passaram a publicar matérias e editoriais praticamente todas as semanas contestando os processos de diversas comunidades, sobretudo da llha da Marambaia, mas também de Sacopã (RJ), Invernada dos Negros (SC) e de comunidades de Santo Antônio do Guaporé (RR), do Sapê do Norte (ES), entre outras. Embora os ataques da mídia fossem direcionados a casos específicos, a estratégia era clara: questionar todo o arcabouço legal referente à regularização das comunidades quilombolas. O alvo principal não por acaso era o mesmo apontado pela ADI 3.239/2004: o critério de autoidentificação para definir quem são os grupos quilombolas, atribuindo aos antropólogos, às ONGs e assessorias uma postura tendenciosa e sem embasamento científico - apenas ideológico - para destinar terras a grupos oportunistas e falsários. Cabe também destacar que muitas matérias tinham como foco a potencial ameaça que a legislação quilombola representa ao direito de propriedade e ao meio ambiente.

Essa campanha midiática assumiu proporção tal que fez com que a Fundação Cultural Palmares (FCP) instaurasse, em julho de 2007, uma sindicância para apurar as supostas denúncias de fraude. Em setembro, a FCP concluiu a sindicância e atestou a legitimidade de todas as certidões até então emitidas. O ataque, porém, não cessou, e o site Observatório Quilombola chegou a criar o "Dossiê Imprensa Anti-Quilombola" (KOINONIA, 2007), que reúne as matérias divulgadas cujos conteúdos pendiam inequivocamente contra essas populações.

O GT Combate ao Racismo Ambiental, vinculado à Rede Brasileira de Justiça Ambiental (RBJA), o Centro de Direito à Moradia

6 O ano de 2006 foi o que teve mais certidões de autorreconhecimento emitidas pela FCP (417 certidões), o que possivelmente estimulou o acirramento da "campanha antiquilombola" no ano seguinte, 2007. Das 1.820 certidões emitidas pela FCP até agosto de 2011, 1.119 foram emitidas de 2006 em diante, o que mostra a maior demanda por reconhecimento a partir desse ano. (FUNDAÇÃO CULTURAL PALMARES, s/d) 
e Contra Despejos (Cohre), a Comissão Pró-Índio de São Paulo (CPI-SP), a Justiça Global, entre outras organizações da sociedade civil, também passaram a divulgar e rebater as matérias contra os quilombolas. A mídia tornou-se, assim, outra arena de conflito, na qual os veículos a favor dos quilombolas tentavam fazer um contrapeso, mas sem conseguir penetração nos maiores meios de comunicação, que não cederam espaço para as respostas às acusações e, com isso, bloqueando o acesso ao público mais amplo (PERALTA, 2012, p. 65).

Cumpre ressaltar que a votação da ADI 3.239/2004 também não ficou alheia à influência da grande mídia. Basta lembrar que o Ministro Peluso (relator da ação) concluiu seu voto contrário à manutenção do Decreto 4.887/2003 fazendo referência ao que vira nos meios de comunicação. Segundo Peluso, as matérias publicadas atribuíam ao referido decreto o "crescimento de conflitos agrários e incitamento à revolta" (BRASIL, 2018 , p. 49). Nitidamente de acordo com a crítica ao critério de autoreconhecimento, o Ministro menciona reportagens que traziam à tona a "absurda reivindicação de terras e uma explosão de comunidades que passaram a se intitular quilombolas" (BRASIL, 2018, p. 56).

Assim, ao analisarmos o conjunto de instituições amigas da corte e demais atores que se posicionaram contra a manutenção do Decreto $4.887 / 2003$, é inevitável perceber que representam os setores que historicamente se opõem não só aos direitos quilombolas, como também aos dos movimentos indígena e do campo em geral.

\section{APESAR DA VITÓRIA NO STF, MARCO LEGAL ADMINISTRATIVO ANTERIOR AINDA IMPÕE ENTRAVES À TITULAÇÃO}

Elencar os atores que participaram do julgamento da inconstitucionalidade do Decreto 4.887/2003 nos serve aqui por ser um episódio ilustrativo de um quadro de confronto muito mais amplo, que invariavelmente se instaura em disputas por terra ou acesso a recursos naturais, ao que se convencionou chamar de conflitos ecológicos distributivos (MARTíNEZ 
ALIER, 2007), ou conflitos socioambientais (LITTLE, 2006), que configuram o campo preferencial de estudo do marco analítico da Ecologia Política e dos movimentos por Justiça Ambiental (ACSELRAD; MELLO; BEZERRA, 2009; PACHECO; HERCULANO, 2006; ALIMONDA, 2002; MARTÍNEZ ALIER, 2007; entre outros). Sendo assim, ainda que nem todos os argumentos utilizados pelos antagonistas dos quilombolas se apliquem a todas as situações locais de conflito, uma análise mais detida do conjunto desses discursos revela o que está verdadeiramente em conflito: a apropriação de recursos naturais, o controle sobre esses territórios/paisagens e a concepção de desenvolvimento (ALIMONDA, 2002; ESCOBAR, 2005; RADOMSKY; 2011).

Com a atual "frente de expansão de fronteiras" (LITTLE, 2002), os conflitos socioambientais em todo o país recrudesceram e, portanto, embora a vitória quilombola no julgamento da ADI 3.239/2004 tenha sido notável, sabe-se que esse desfecho positivo no judiciário não é garantia de que os milhares de comunidades quilombolas receberão os respectivos títulos em um prazo razoável. Isso porque, para além dos opositores tradicionalmente presentes em âmbito nacional, cada vez mais atores "fantasmagóricos" vêm incidindo na paisagem quilombola e dos demais povos e comunidades tradicionais, notadamente, grupos transnacionais das áreas de mineração, recursos hídricos, agropecuário, alimentar, fundos de pensão estrangeiros, turismo, entre outros.

Assim, embora o Decreto 4.887/2003 tenha sido validado pelo STF, os procedimentos do processo administrativo "para identificação, reconhecimento, delimitação, demarcação, desintrusão, titulação e registro das terras ocupadas pelos remanescentes de comunidades dos quilombos" continuam impondo obstáculos à efetivação dos direitos territoriais quilombolas.

Como resultado das investidas de setores antagônicos, os empecilhos burocráticos nos procedimentos só aumentaram. Entre 2004 e 2009, o Incra alterou a Instrução Normativa - instrumento que define os passos do processo de titulação - quatro vezes ${ }^{7}$. Os impasses e

7 As mudanças na legislação contrariam a C169 da OIT, cujo Artigo $6^{\circ}$ determina que os povos interessados deverão ser consultados cada vez que sejam previstas medidas 
reviravoltas que marcaram a última alteração da IN do Incra demonstram que em grande parte esses retrocessos se deveram não apenas ao poderio dos antagonistas históricos, mas também à oposição de setores de dentro do próprio governo que havia criado o Decreto, que assim revelou uma postura ambígua diante da causa quilombola.

Em 2008, a Advocacia Geral da União (AGU), que passou a ser o agente de interlocução do governo com o movimento quilombola, na figura da Conaq, argumentava que, para "salvar o Decreto 4.887/2003", era preciso mudar mais uma vez a instrução normativa do Incra (IN n. 20 naquele então) - e de fato na época havia a iminência da votação pelo Supremo Tribunal Federal (STF) da ADI 3.239/2004, impetrada pelo Partido dos Democratas (DEM), e ocorria a tramitação do já mencionado PDL n. 44 do Deputado Federal Valdir Collato (PMDB/SC).

Pressionado pelo movimento quilombola e pelas organizações de apoio, o governo federal concordou em promover uma Consulta Nacional Quilombola, realizada em Brasília entre os dias 15 e 17 de abril de 2008, contando com a presença de cerca de 300 quilombolas de todo o país. A composição da comitiva do governo, com membros dos principais órgãos, como AGU, Casa Civil, Seppir, FCP, Incra, MDA, Ibama e GSI, refletiu a importância dada ao tema de regularização fundiária de territórios quilombolas, ainda que não no sentido de agilizar os processos (PERALTA, 2008). Ao final do evento, não houve consenso entre governo e quilombolas, que inclusive denunciaram que aquele encontro não atendia aos preceitos de uma consulta legítima, ou seja, prévia, livre e informada, e sim representava uma mera exposição da nova normativa preparada pelo governo.

Apesar da explícita rejeição do movimento quilombola e de suas assessorias e das diversas manifestações contrárias às mudanças, o governo publicou em setembro de 2008 a IN. 49 no Diário Oficial da União, o que significou que o governo cedeu aos anseios dos setores antiquilombolas. Segundo avaliação da Comissão Pró-Índio de São Paulo (CPI-SP) que realiza acompanhamento da legislação quilombola:

legislativas ou administrativas suscetíveis de afetá-los diretamente (OIT, 1989). 
As exigências introduzidas a cada nova norma tornaram o processo mais moroso e custoso e, consequentemente, mais difícil de ser concluído (...). É difícil aceitar que a motivação de tais mudanças seja realmente aquela anunciada pelo governo: a necessidade de aperfeiçoar as normas a fim de dar segurança jurídica ao processo e evitar futuros conflitos no judiciário. Em setembro de 2009, a Instrução Normativa do Incra 49/2008 completou um ano de existência e, ao contrário do anunciado pelo governo, não se percebeu qualquer avanço na condução dos processos ou na resolução dos conflitos em função das novas regras. As sucessivas normas parecem ser muito mais uma concessão aos setores que manifestaram forte oposição aos direitos quilombolas do que um aperfeiçoamento. (CPI-SP, 2010, p. 3) ${ }^{8}$

Em 2009, setores progressistas dentro do próprio Incra conseguiram revogar a IN. 49, gesto que foi rapidamente reprimido pelo alto escalão do governo. No mesmo mês de outubro, a instrução de número 56 foi revogada voltando a valer a de número 49 , que foi republicada como IN. 57, vigente atualmente. Segundo funcionários do Incra, esse movimento foi contido "devido à pressão de setores que são favoráveis a manutenção dos entraves na política de regularização" (REPÓRTER BRASIL, 2010).

Como reação, os servidores do Setor Quilombola do Incra divulgaram o documento intitulado "Carta moção de repúdio ao governo pelo descaso apresentado em relação a luta pela regularização de territórios quilombolas", em que criticavam o número insuficiente de servidores e denunciavam a total falta de condições para realizar suas funções:

As equipes que se formaram foram aos poucos se estruturando fisicamente e lutaram com todas as armas para executar o que Ihes competiam. Enfrentaram problemas como a falta equipamentos, a falta de quadro técnico e, como não podia faltar, a oposição direta de setores tradicionais que advogam a favor da manutenção do latifúndio nas mãos de uma elite ruralista. Es-

8 Além disso, a IN não exige o mesmo grau de complexidade das contestações e, portanto, ao mesmo tempo em que burocratiza a elaboração do RTID para a identificação dos territórios, garante todas as facilidades a terceiros para contestá-lo (PERALTA, 2008). 
ses setores tradicionalistas da sociedade impuseram inúmeros constrangimentos aos funcionários que trabalham com o setor quilombola no Incra. Houve coerção física, retaliações civis e administrativas e até mesmo ameaças de morte. (REPÓRTER BRASIL, 2010)

Diante desse quadro de violações, o Ministério Público Federal (MPF) decidiu, em novembro de 2009, instaurar inquérito civil público para apurar a situação geral das políticas públicas destinadas à garantia do direito à terra das comunidades quilombolas no Brasil. Nele, o Grupo de Trabalho de Quilombos e Populações Tradicionais da $6^{a}$ Câmara de Coordenação e Revisão solicitou ao Incra dados sobre a estrutura administrativa da autarquia relacionada à regularização fundiária de terras quilombolas. Para o GT, "o quadro geral relativo às políticas públicas voltadas ao atendimento da população quilombola, em especial da sua garantia do direito à terra, é alarmante e denota grave e sistemática violação a direitos fundamentais positivados na Constituição Federal e em tratados internacionais de que o Brasil é parte" (TERRA DE DIREITOS, 2010)

No ano de 2010, em sua Nota Técnica n. 168 intitulada Orçamento Quilombola 2008-2010 e a maquiagem na titulação, o Instituto Nacional de Estudos Socioeconômicos (Inesc) demonstrava o baixo desempenho financeiro das ações destinadas ao reconhecimento, demarcação, titulação e desintrusão dos territórios quilombolas, tendência verificada desde 2007, quando o Inesc começou a monitorar o Orçamento Quilombola, instituído em 2004. Em 2009, por exemplo, $\mathrm{R} \$ 6,8$ milhões deixaram de ser aplicados no reconhecimento, demarcação e titulação de "áreas remanescentes de quilombo"; e dos R $\$ 28,3$ miIhões autorizados para indenização aos ocupantes das terras demarcadas e tituladas, foram utilizados somente $6,52 \%$. Segundo o autor da Nota Técnica, Ricardo Verdum, a expressão maquiagem se deve à constatação de que o governo federal só estaria titulando - e ainda assim em número bastante reduzido - terras devolutas, terras públicas pertencentes a estados ou aquelas onde não há "maiores dificuldades de aquisição", o que deixa de fora grande parte das áreas quilombolas (VERDUM, 2010). 
Como vimos, tanto antes como depois da publicação da nova IN do Incra em 2010, o número de titulações avançou a passos lentos. Muitos casos de conflitos foram encaminhados à Casa Civil da Presidência da República que estabeleceu Câmaras de Conciliação coordenadas pela AGU, criando assim um processo político paralelo ao processo administrativo conduzido pelo Incra. Volta e meia, a votação da ADI 3.239/2004 surgia para atormentar o movimento quilombola, que se via obrigado a mobilizar lideranças e aliados, sendo que, por duas vezes, após toda a árdua mobilização para levar representantes para assistir a votação, ministros se davam ao luxo de simplesmente não comparecer, postergando uma vez mais o desfecho, que, como sabemos, foi feliz, embora não sem muito desgaste. Segundo declarou Erica Monteiro, liderança quilombola do Pará, o adiamento era uma tentativa de desmobilizar as comunidades: "é uma estratégia que eles estão usando para nos desmobilizar, porque a cada data que eles marcam para julgar a gente se organiza, se mobiliza, põe quilombola em Brasília." (CAMPELO, 2017).

O Estatuto da Igualdade Racial, promulgado em junho de 2010, foi outra frente de luta em que a causa quilombola sofreu revezes. Após dez anos de negociações no plano legislativo, o Estatuto foi finalmente promulgado, ainda que marcado por muitos retrocessos, entre eles, a perda de sua força normativa, assumindo a forma meramente autorizativa. Apesar do nome, o Estatuto da Igualdade Racial teve suprimida toda e qualquer menção à palavra "raça". Também foi retirada do texto a garantia de cotas raciais em estabelecimentos de educação superior e suprimido todo o capítulo referente à titulação de territórios quilombolas (SILVA, 2012).

Além disso, se desde 2004 a execução do orçamento quilombola vinha sendo acompanhada com apreensão, após o golpe de 2016 que destituiu a Presidenta Dilma Rousseff, os recursos do governo destinados a essa população sofreram cortes históricos, inviabilizando toda a política quilombola, conforme mostra o gráfico a seguir. 
Gráfico 1. Orçamento federal previsto para indenização de territórios quilombolas

\section{ORCAMENTO FEDEBAL PREVISTO PARA INDENIZAÇAO DE TERRITORIOS QUVILMBOLAS}

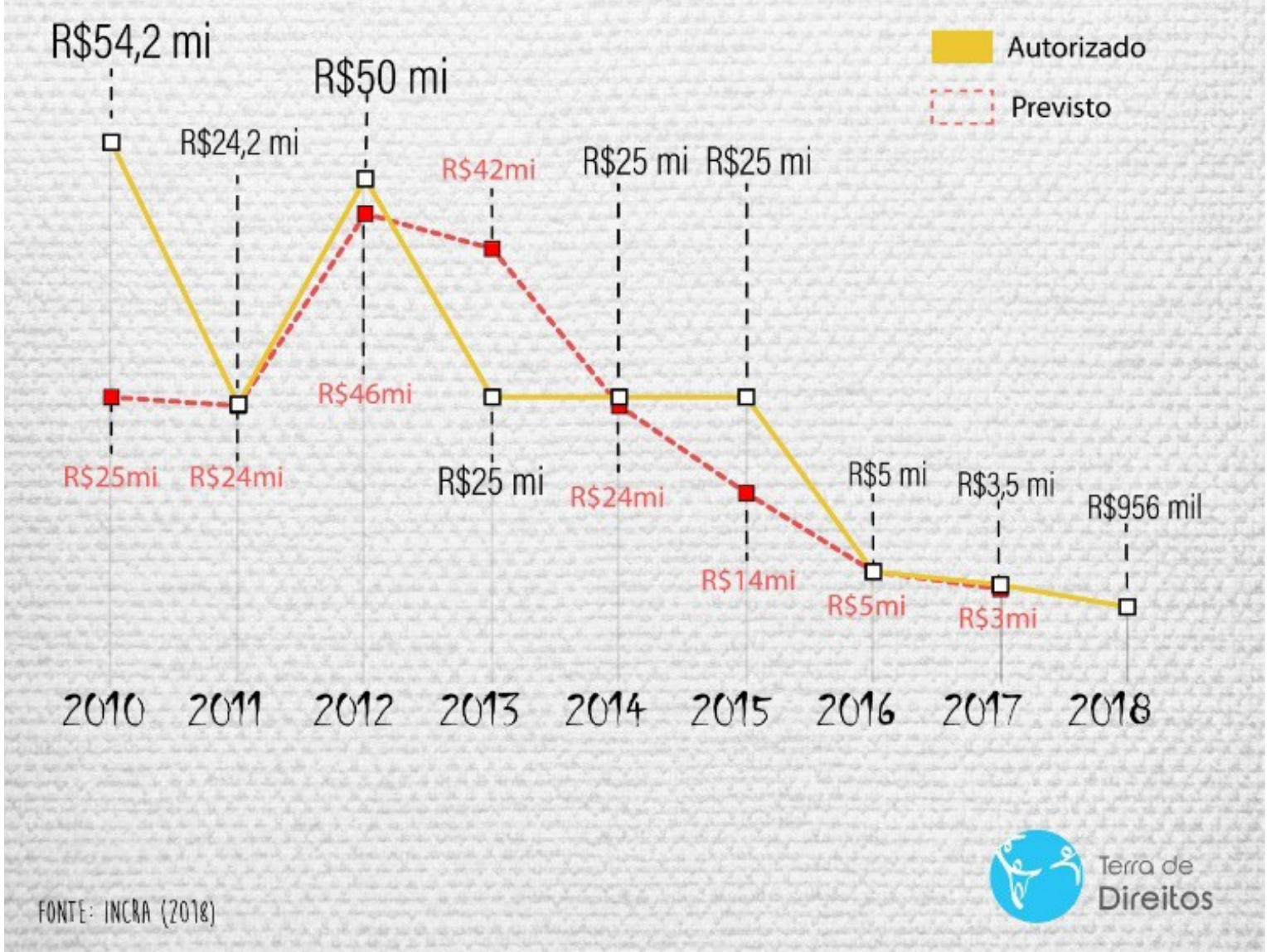

Fonte: Incra (Terra de Direitos, 2018)

Como se não bastasse, em março de 2017, o governo federal tornou público o contingenciamento do orçamento para cumprir com as limitações estabelecidas pela Proposta de Emenda Constitucional $n$. 95 (PEC 95), conhecida como PEC do Fim do Mundo. Esse contingenciamento representou um corte orçamentário de $44 \%$ para o Ministério do Desenvolvimento Social, $41 \%$, para o Ministério da Cultura e 18\% para o Ministério da Educação (CONAQ, 2018). Segundo de- 
núncia enviada recentemente à Comissão Interamericana de Direitos Humanos (CIDH):

Esta diminuição orçamentária impacta, automaticamente, nas políticas públicas que buscavam garantir os direitos quilombolas. Assim, a proteção de defensoras e defensores de direitos humanos quilombolas, a titulação de terras quilombolas e a permanências de estudantes quilombolas nas Universidades públicas brasileiras, por exemplo, são algumas das políticas que se veem severamente impactadas com os cortes promovidos pelo governo federal. (CONAQ, 2018, p. 3)

Também foi depois do golpe de 2016 que o governo Temer transferiu de ministérios três vezes - em questão de meses - a atribuição da política quilombola (DOLCE, 2016) com o nítido propósito de estagnar os processos de regularização fundiária em curso.

Mas o retrato mais cruel da conjuntura quilombola é o aumento do número de quilombolas assassinados, que em 2017 atingiu a marca de 14 assassinatos (CONAQ, 2018). Também segundo denúncia encaminhada pela Conaq e organizações sociais brasileiras à $\mathrm{CIDH}$, esse crescimento acompanha a tendência nacional de aumento no número de assassinatos de defensores e defensoras de direitos humanos na luta por seus territórios e estaria relacionado à falta de garantia dos direitos territoriais quilombolas.

Isto porque, sem o reconhecimento oficial do Estado, os quilombos ficam mais vulneráveis às pressões de latifundiários, grileiros e mineradoras. Percebe-se, ademais, que à medida que o processo de titulação dos territórios avança, também a violência se acirra. (CONAQ, 2018, p. 15)

Esse retrospecto do contexto e dos atores incidentes nos conflitos envolvendo quilombolas nos permite visualizar as várias estratégias e frentes de oposição à regularização dos territórios quilombolas, desde o plano legislativo, passando pelo orçamentário e culminando com ameaças e assassinatos de lideranças, mas sempre tendo como fundo a manutenção das cotas de poder com vistas à apropriação de 
terras e recursos incidentes nesses territórios negros. Com isso, ainda que seja válido reconhecer a dimensão da conquista junto ao STF, não se deve deixar de observar os limites que tal decisão representa para o acesso seguro dos quilombolas a seus territórios ancestrais.

\section{ESTRATÉGIA QUILOMBOLA: ANTIGOS OPONENTES, NOVAS ALIANÇAS}

Para fazer frente às investidas antagônicas, as organizações representativas quilombolas, ainda que não de forma homogênea, têm buscado se articular com outros setores, como os ligados às lutas por direitos humanos, reforma agrária e superação do racismo, entre eles: Movimento Negro, Via Campesina, Movimento Indígena, Movimento dos Trabalhadores Sem-Terra (MST), Fórum Brasileiro de Reforma Agrária, Associações de Jornalistas Negros, Rede Nacional de Advogados Populares, Articulação Nacional de Agroecologia (ANA), Movimento dos Atingidos por Barragens (MAB), entre outros.

Essa articulação, não raro, estabelece interfaces com movimentos de cunho ambiental, o que também tem se mostrado estratégico para legitimar a luta pelos direitos étnicos e territoriais dessas comunidades (PERALTA, 2012). Há diversos exemplos de comunidades quilombolas que já estabeleceram contatos relevantes com redes ou organizações de base ambientalista (MARTINEZ ALIER, 2007). É o caso das comunidades quilombolas do Norte do Espírito Santo, da região conhecida como Sapê do Norte, que integram a Rede Alerta Contra o Deserto Verde, opondo-se à monocultura de eucalipto de empresas como a Aracruz Celulose. No Rio de Janeiro, o caso da comunidade da llha da Marambaia foi frequentemente abordado pela Rede Brasileira de Justiça Ambiental (RBJA). Diante do conflito com a Marinha de Guerra do Brasil, a comunidade ganhou mais adesões ao atribuir à sua demanda territorial a defesa do patrimônio ambiental.

Mas o fato é que, ainda que suas alianças não sejam com redes ou movimentos explícita ou especificamente ambientalistas (MARTINEZ ALIER, 2007), o movimento quilombola tem apresentado a 
seguinte tendência de movimentos sociais dos países do Sul, como nos afirma Leff (2008):

Por sua vez, os movimentos ambientalistas nos países pobres surgem em resposta à destruição da natureza e ao esbulho de suas formas de vida e de seus meios de produção; são movimentos desencadeados por conflitos sobre o acesso e o controle dos recursos; são movimentos pela reapropriação social da natureza vinculados a processos de democratização, à defesa de seus territórios, de suas identidades étnicas, de sua autonomia política e sua capacidade de autogerir suas formas de vida e seus estilos de desenvolvimento. (p. 114)

Apesar dessa convergência, muitos setores ambientalistas ainda assumem posição conservacionista extremada, inclinada à retirada de áreas de preservação não só de comunidades quilombolas, mas de outras populações tradicionais. Em maio de 2009, em matéria intitulada "AGU, Incra e MDA querem acelerar acordos para titulação de áreas quilombolas em unidades de conservação" (ROSSI, 2009), a Advocacia Geral da União (AGU) divulga a existência de seis processos em andamento nas Câmaras de Conciliação da AGU em que territórios de comunidades quilombolas estão em conflito com áreas de unidades de conservação ambiental protegidas pelo Ibama e pelo ICMBio9.

Já Henyo T. Barreto Filho (2006), ao discorrer sobre os casos em que a presença de grupos humanos em áreas protegidas é tolerada/ permitida, atenta para o fato de que muitas vezes os planejadores e formuladores - seja da comunidade científica, da sociedade civil ou ainda de órgãos do governo responsáveis pela política ambiental - podem atuar como agentes de controle e repressão dessas populações, embora essa postura não seja tão evidente a princípio.

9 Os territórios quilombolas envolvidos são: Alto Trombetas, Jamari/Último Quilombo e Moura (PA) X Reserva Biológica do Rio Trombetas, Floresta Nacional Saracá-Taquera e Floresta Estadual Trombetas; o Quilombo do Tambor (AM) X Parque Nacional do Jaú; a comunidade Santo Antônio do Guaporé (RO) X Reserva Biológica do Guaporé; a comunidade do Cunani (AP) X Parque Nacional do Cabo Orange; o Quilombo Mumbuca (MG) X Reserva Biológica da Mata Escura; e a comunidade de São Roque (SC) X os Parques Nacionais da Serra Geral e Aparados da Serra. 
O reconhecimento de que as instituições nativas funcionam, portanto, subordina-se ao interesse prático dos estudos e à preocupação marcada com a harmonização das situações de conflito e das relações assimétricas dominantes no estabelecimento de decisões de manejo. Esta é uma tarefa prática que, nos marcos desse modelo de conservação, os cientistas sociais têm sido chamados a cumprir. (...) O planejamento de áreas protegidas sensível à dimensão cultural justifica-se, assim, em função do desejo de implementá-las a baixo custo social, harmonizando os conflitos e assimetrias (BARRETO FILHO, 2006, p. 6).

Porém, a situação crítica do esgotamento de recursos naturais e as pesquisas empíricas das últimas décadas sobre os modos de vida das comunidades tradicionais apontam que essas áreas estarão mais bem conservadas sob a gestão comum desses grupos do que sob a tutela do Estado ou de agentes privados (DIETZ et al., 2002), fazendo com que se reconheçam efetivamente os direitos étnicos e territoriais desses povos tradicionais, entre os quais se destacam a "autodeterminação" (BARRETO FILHO, 2006). Nessa mesma linha, podemos nos referir também à reflexão em torno à noção de que atualmente está em curso um processo de "ambientalização dos conflitos sociais", relacionado à construção de uma nova questão social, uma nova questão pública, tendo a "questão ambiental como nova fonte de legitimidade e de argumentação nos conflitos" (LOPES, 2006).

No que se refere à atuação do judiciário, embora este seja considerado um setor conservador, tem adotado posturas até certo ponto progressistas em casos envolvendo populações tradicionais. A seguir, decisões da justiça que beneficiaram as comunidades quilombolas, contrapondo-se a particulares ou a órgãos do próprio governo: Ilha da Marambaia (RJ), em 2010; Acauã (RN), 2011; Pedra do Sal (RJ), 2008; Alcântara (MA), 2008; Invernada dos Negros (SC), 2009. São casos cujas vitórias de processos locais têm repercussão no cenário nacional, servindo de jurisprudência, uma vez que todas essas decisões julgaram o artigo 68 como sendo autoaplicável e defenderam o critério de autoatribuição presente no Decreto 4.887/2003 em função de sua 
previsão em acordos internacionais, notadamente a Convenção 169 da OIT (CPI-SP, 2018).

Segundo depoimento de Felício Pontes, procurador geral do Ministério Público Federal do Pará, à Carta Maior (GLASS, 2007), "o judiciário tem sido mais afeito a aceitar a regularização fundiária demandada por populações tradicionais do que por movimentos de luta pela terra, como o MST e as organizações sindicais".

Para Almeida (GLASS, 2007), essa aceitação no judiciário tem a ver com a articulação política dessas populações:

A melhor arma dos movimentos sociais e comunitários é o inter-relacionamento e o investimento em organização, num movimento contrário ao isolacionismo e à "manutenção da pureza" dos grupos tradicionais. "Os quilombolas no Brasil estão se fortalecendo porque estão se relacionando", exemplifica.

\section{AVANÇOS E PERSPECTIVAS DE LUTA}

Mesmo sob o poderoso arsenal dos antagonistas, o movimento quilombola tem efetivamente muita razão em comemorar a vitória no STF. Após uma batalha que durou 13 anos, além da decisão pela constitucionalidade do Decreto 4.887/2003, a noção de marco temporal para fixar uma data a partir da qual os direitos territoriais quilombolas teriam validade também foi derrubada. Tais conquistas são muito significativas, ainda mais se considerarmos a recente explicitação do caráter conservador e elitista da Suprema Corte, com direito à transmissão ao vivo de julgamentos, o que parece não constranger os ministros.

Mesmo em meio a um contexto de muitos retrocessos em termos de garantia de direitos da população brasileira, nos quais a figura do STF vem se fazendo presente, os quilombolas vêm acumulando outras vitórias. Segundo dados levantados pela CPI-SP, apenas um mês após a decisão do STF a favor do marco legal quilombola, o Iterpa entregou os títulos de propriedade a quatro terras no Pará: Cachoeira Porteira, São Tomé do Tauaçu, Ramal do Caeté e Espírito Santo. O Pará é o 
estado que figura não só como o primeiro a ter uma terra titulada (Boa Vista, em 1995), como o que contabiliza mais títulos, 63 , sendo que grande parte deles, 55, foram emitidos pelo Iterpa, enquanto apenas oito foram outorgados via processo do Incra, pelo governo federal. Já em julho de 2017, por meio de um processo de negociação entre quilombolas e governo federal, o Incra publicou as portarias de reconhecimento e declaração dos territórios de Alto Trombetas I e II, de modo a atender à decisão judicial que fixou um prazo de dois anos para sua titulação.

Outras comunidades vêm também se mobilizando para resistir à pressão para reduzirem sua demanda territorial. É o caso de Mesquita, comunidade situada no estado de Goiás. Em seu blog, a CPI-SP expõe o contexto, inclusive com base em informações veiculadas pela mídia do que estaria em jogo:

Dos 4.151,3707 hectares identificados no Relatório de Identificação (RTID) em 2011 deverão ser reconhecidos, através da Portaria da Presidência do Incra, somente 971,4285 hectares, o que significa uma redução $82 \%$ do território identificado e delimitado pelo próprio Incra mediante estudos técnicos estabelecidos em normativos internos.

Segundo informações publicadas pelo jornal O Globo, a diminuição visa beneficiar o ex-presidente José Sarney, um dos sócios de empresa proprietária da área sobreposta à terra quilombola. Ainda segundo o jornal, a articulação para que a alteração ocorresse envolveu o deputado federal Jovanir Arantes (PTB - GO) e seu sobrinho Rogério Arantes, à época, diretor de Ordenamento da Estrutura Fundiária (DF) do órgão, diretoria a que responde a Coordenação-Geral de Regularização de Territórios Quilombolas (DFQ). Rogério foi exonerado do cargo no início de junho após ter mandado de prisão decretado por suspeita de participação em esquema de corrupção no Ministério do Trabalho. (CPI-SP, 2018)

O movimento quilombola também vem se aliando a organizações da sociedade civil para apresentar denúncias formais a órgãos internacionais de Direitos Humanos. Em junho de 2017, foi enviado um informe à Comissão Interamericana de Direitos Humanos (CIDH). Em outubro 
do mesmo ano, lideranças participaram de uma audiência por ocasião do $165^{\circ}$ Período de Sessões desta Comissão Interamericana de Direitos Humanos, em Montevidéu, no Uruguai.

A formação de quadros quilombolas em agroecologia, protagonismo político, articulação política, fortalecimento institucional, no ambiente acadêmico e na vida político-partidária também despontam como estratégias de correlação de forças no âmbito dos conflitos incidentes na paisagem quilombola, desde o nível micro ao macro (PERALTA, 2012). Recentemente, o IBGE divulgou estar desenvolvendo uma metodologia para incorporar dados sobre as comunidades quilombolas em todo o país a partir do próximo Censo Demográfico, em 2020, assim como o IPHAN reconheceu o Sistema Agrícola Tradicional (SAT) das Comunidades Quilombolas do Vale do Ribeira (SP) como Patrimônio Cultural Brasileiro, reafirmando a crescente capacidade de resiliência do movimento quilombola, mesmo em meio a talvez o cenário político mais adverso desde a promulgação da Constituição Cidadã em 1988.

\section{CONCLUSÃO}

Se o golpe que derrubou a Presidente Dilma é muitas vezes referido como de cunho político-jurídico-midiático, não por coincidência encontramos os mesmos atores entre os principais oponentes aos direitos quilombolas (como também a outros movimentos do campo, povos indígenas e comunidades tradicionais).

Entretanto, independente dos passos lentos do campo jurídico-administrativo e das perspectivas de dias ainda mais sombrios pós-eleições 2018, as comunidades quilombolas estão resistindo agora, no momento em que lemos estas linhas, buscando legitimar sua soberania. Após essa, talvez exaustiva, ainda que obviamente não completa, descrição dos embates travados pelo movimento quilombola, podemos constatar que os conflitos socioambientais não ocorrem apenas no campo, mas também em gabinetes governamentais, em escritórios de grandes empresas e na mídia. Os quilombos (re)existem, e continuarão (re)existindo, sem baixar a guarda. Afinal, o território quilombola não é a luta, mas a vida em si e, portanto, não há alternativa a não ser vivê-la. 


\section{REFERÊNCIAS BIBLIOGRÁFICAS}

ACSELRAD, Henri; MELLO, Cecília; BEZERRA, Gustavo. O que é justiça ambiental. Rio de Janeiro: Garamond, 2009.

ADVOCACIA GERAL DA UNIÃO. AGU, Incra e MDA querem acelerar acordos para titulação de áreas quilombolas em unidades de conservação ambiental. Disponível em: <http://www.agu.gov.br/ sistemas/site/TemplatelmagemTexto.aspx?idConteudo=83282\&id_ site=3>. Acesso em: 20 de março de 2012.

ALIMONDA, H. A. (Org.). Ecología Política: naturaleza, sociedad y utopía. Buenos Aires: CLACSO, 2002.

ALMEIDA, Alfredo Wagner B. de. Povos e comunidades tradicionais atingidos por conflitos de terras e atos de violência. Conflitos no Campo Brasil 2009. São Paulo: Expressão Popular, 2010.

. OS QUILOMBOLAS: o direito étnico à terra. Boletim Orçamento \& Política Socioambiental - INESC, v. 4, n. 13, jun. 2005.

- Terras de Preto, Terras de Santo, Terras de Índio - uso comum e conflito. In: HÁBETTE, J.; CASTRO, Edna (Org.) Na trilha dos grandes projetos. Belém: NAEA/UFPA, 1989.

BARRETTO FILHO, Henyo. Populações tradicionais: introdução à crítica da ecologia política de uma noção. In: ADAMS, Cristina; MURRIETA, Rui; NEVES, Walter (Orgs.). Sociedades Caboclas Amazônicas: modernidade e invisibilidade. São Paulo, Annablume, 2006. p. 109-143.

BRASIL. Supremo Tribunal Federal. Acórdão n 3.239. Relator: Ministro Cezar Peluso. Sessão de 08/2/2018. Disponível em: <http://redir.stf. jus.br/paginadorpub/paginador.jsp?docTP=TP\&doclD=749028916>. Acesso em: 10 mar. 2019.

Lei n. 12.288, de 20 de julho de 2010. Institui o Estatuto da Igualdade Racial; altera as Leis n. 7.716, de 5 de janeiro de 1989, 9.029, de 13 de abril de 1995, 7.347, de 24 de julho de 1985, e 10.778, de 
24 de novembro de 2003. Disponível em: <http://www.planalto.gov.br/ ccivil_03/_ato2007-2010/2010/lei//12288.htm>. Acesso em: 20 jul. 2018.

. Decreto n. 5.051, de 19 de abril de 2004. Promulga a Convenção 169 da Organização Internacional do Trabalho - OIT sobre Povos Indígenas e Tribais. Disponível em:<http://www.planalto.gov.br/ ccivil_03/_ato2004-2006/2004/decreto/d5051.htm.> Acesso em: 20 jun. 2018.

. Decreto n. 4.887, de 20 de novembro de 2003. Regulamenta o procedimento para a identificação, reconhecimento, delimitação, demarcação e titulação das terras ocupadas por remanescentes das comunidades dos quilombos de que trata o art. 68 dos Atos das Disposições Constitucionais Transitórias. Disponível em: <http//:www. planalto.gov.br/ccivil_03/_ato2007-2010/2007/decreto/d6040.htm> Acesso em: 20 jun. 2018.

. Constituição (1988). Disponível em: <http//:www.planalto.gov. br/ccivil_03/Constituicao/Constituicao.htm> Acesso em: 20 jun. 2018.

CAMPELO, Lilian. Adiamento da ação que questiona terras quilombolas visa desmobilizar luta, diz líder. In: Brasil de Fato. São Paulo, 16 de agosto de 2017. Disponível em: <https://www.brasildefato.com. br/2017/08/16/adiamento-da-acao-que-questiona-terras-quilombolasvisa-desmobilizar-luta-diz-lider/>. Acesso em: 20 ago. 2018.

COLLATO, Valdir. MCT quer garantir o direito de propriedade. Disponível em: <http://www.valdircolattoweb.com.br/arquivos_internos/ index.php?abrir=mct>. Acesso em: 18 de outubro 2010.

COMISSÃOPRÓ-ÍNDIODESÃO PAULO. Comunidades Quilombolas. Disponível em:<www.cpisp.org.br/>. Acesso em: 27 de setembro 2018.

. Terras Quilombolas Acauã e Kalunga parcialmente tituladas pelo Incra em maio. Revista Comissão Pró-Índio de São Paulo. Disponível em: <http://comissaoproindio.blogspot.com/2018/06/terrasquilombolas-acua-e-kalunga.html>. Acesso em: 18 jul. 2018. 
. Terras Quilombolas: Balanço 2009. Disponível em: <http:// cpisp.org.br/publicacao/balanco-terras-quilombolas-2009/>. Acesso em: 20 jul. 2018.

COORDENAÇÃO NACIONAL DE ARTICULAÇÃO DAS COMUNIDADES NEGRAS RURAIS QUILOMBOLAS (CONAQ). Violência contra quilombolas dispara em 2017. Disponível em: $\quad<$ http://conaq.org.br/noticias/violencia-contra-quilombolasdispara-em-2017/>. Acesso em: 22 set. 2018.

DIETZ, Tomas; DOLSAK, Nives; OSTROM, Elinor; STERN, Paul. The Drama of the Commons. Washington: National Academy Press, 2002.

DOLCE, Julia. Política para terras quilombolas foi transferida de ministério três vezes. In: Brasil de Fato. 9 dejunho de 2016. Disponível em: <https://www.brasildefato.com.br/2016/06/10/politica-para-terrasquilombolas-foi-transferida-de-ministerio-tres-vezes/>. Acesso em: 20 jul. 2018.

ESCOBAR, Arturo. El "postdesarrollo" como concepto y práctica social. In: MATO, Daniel (Coord.). Políticas de economía, ambiente y sociedad en tiempos de globalización. Caracas: Facultad de Ciencias Económicas y Sociales, Universidad Central de Venezuela, 2005. p. 17-31.

FUNDAÇÃO CULTURAL PALMARES. Certificação Quilombola. Disponível em: <http://www.palmares.gov.br/?page_id=37551>. Acesso em: 27 set. 2018.

GLASS, Verena. Reconhecimento do conceito de populações tradicionais facilita acesso à terra. In: Carta Maior. Recife, 22 de março de 2007. Disponível em: <https://www.cartamaior.com.br/?/Editoria/ Movimentos-Sociais/Reconhecimento-do-conceito-de-populacoestradicionais-facilita-acesso-a-terra/2/12971>. Acesso em: 27 set. 2018.

GUIMARÃES, Cátia. Censo agropecuário: que realidade do campo brasileiro se quer mostrar? In: EPSJV/Fiocruz, 4 maio 2017. Disponível em:<http://www.epsjv.fiocruz.br/noticias/reportagem/censo-agropecua 
rio-que-realidade-do-campo-brasileiro-se-quer-mostrar>. Acesso em: 10 mar. 2019.

INSTITUTO BRASILEIRO DE GEOGRAFIA E ESTATÍSTICA - IBGE. Censo Agropecuário 2006. Disponível em: <https://biblioteca.ibge. gov.br/visualizacao/periodicos/50/agro_2006_agricultura_familiar. pdf>. Acesso em: 27 set. 2018.

INSTITUTO DE PATRIMÔNIO HISTÓRICO E ARTÍSTICO NACIONAL - IPHAN. Sistema Agrícola Tradicional do Vale do Ribeira agora é Patrimônio Cultural do Brasil. 2018.Disponível em:<http://portal. iphan.gov.br/noticias/detalhes/4838/sistema-agricola-tradicional-dovale-do-ribeira-agora-e-patrimonio-cultural-do-brasil>. Acesso em: 22 set. 2018.

KOINONIA PRESENÇA ECUMÊNICA E SERVIÇO. Dossiê AntiQuilombola. Observatório Quilombola. Disponível em: <http://www. koinonia.org.br/oq/dossie_antiquilombola.asp>. Acesso em: 27 jul. 2018.

Quilombos do Sapê do Norte: as comunidades negras rurais dos municípios de Conceição da Barra e São Mateus - ES. Rio de Janeiro: KOINONIA Presença Ecumênica e Serviço, 2005.

LEFF, Enrique. Saber ambiental: sustentabilidade, racionalidade, complexidade, poder. Petrópolis: Vozes, 2008.

LITTLE, Paul E. Territórios Sociais e Povos Tradicionais no Brasil: por uma antropologia da territorialidade. Série Antropologia, Brasília, n. 322, 2002.

- Ecologia política como etnografia: um guia teórico e metodológico. Horizonte antropológico, Porto Alegre, v. 12, n. 25, jan./jun. 2006.

LOPES, J.S. L. Sobre processos de "ambientalização" dos conflitos e sobre dilemas da participação. Horizontes Antropológicos, Porto Alegre, ano 12, n. 25, p. 31-64, jan./jun. 2006. 
MARTÍNEZ ALIER, Joan. O ecologismo dos pobres: conflitos ambientais e linguagens de valoração. São Paulo: Contexto, 2007.

MINISTÉRIO PÚBLICO FEDERAL. Resumo do Julgamento da ADI 3239. 2018. Disponível em: <http://www.mpf.mp.br/atuacao-tematica/ ccr6/dados-da-atuacao/grupos-de-trabalho/gt-quilombos/noticias-edocumentarios/JulgamentoADI 3239.pdf/at_download/file>. Acesso em: 22 jul. 2018.

ORGANIZAÇÃO INTERNACIONAL DO TRABALHO. Convenção n. 169, 1989. Disponível em: <http://www.ilo.org/brasilia/convencoes/ WCMS_236247/lang--pt/index.htm>. Acesso em: 27 set. de 2018.

PACHECO, Tânia; HERCULANO, Selene (Org.). Racismo Ambiental. Rio de Janeiro: Fase, 2006.

PERALTA, Rosa. Desenvolvimento e sustentabilidade: novas interfaces para a luta quilombola. João Pessoa: Programa de Pós-Graduação (Mestrado) em Desenvolvimento e Meio Ambienteda Universidade Federal da Paraíba, 2012.

. Consulta Nacional Quilombola: sujeita a pancadas de chuvas e trovoadas. Revista Tempo e Presença Digital, Rio de Janeiro, v.3, n. 11, jul. 2008. Disponível em: <http://www.koinonia.org.br/tpdigital/ detalhes.asp?cod_artigo $=212 \&$ cod_boletim $=12 \&$ tipo $=$ Artigo $>$. Acesso em: 18 jul. 2017.

PRIOSTE, Fernando. Decreto quilombola é constitucional sem aplicação do marco temporal, afirma STF. In: Terras de Direitos, 9 fev. 2018. Disponível em: <https://terradedireitos.org.br/acervo/artigos/ decreto-quilombola-e-constitucional-sem-aplicacao-do-marcotemporal-afirma-stf/22732>. Acesso em: 20 jul. 2018.

RADOMSKY, Guilherme Francisco Waterloo. Desenvolvimento, pósestruturalismo e pós-desenvolvimento: a crítica da modernidade e a emergência de "modernidades" alternativas. Revista Brasileira de Ciências Sociais, v. 26, n. 75, p. 149-193, fev. 2011. 
REPÓRTER BRASIL. Carta Moção de Repúdio ao Governo pelo descaso apresentado em relação à luta pela regularização de territórios quilombolas. 3 maio 2010. Disponível em: <https:// reporterbrasil.org.br/2010/05/carta-mocao-de-repudio-ao-governopelo-descaso-apresentado-em-relacao-a-luta-pela-regularizacao-deterritorios-quilombolas/>. Acesso em: 22 fev. 2012.

ROSSI, Leticia Verdi. AGU, Incra e MDA querem acelerar acordos para titulação de áreas quilombolas em unidades de conservação ambiental. In: Advocacia Geral da União, 2 jun. 2009. Disponível em: $<$ https://agu.gov.br/page/content/detail/id_conteudo/83282>. Acesso em: 5 maio 2011.

SCHRAMM, Franciele Petry. Orçamento para titulação de territórios quilombolas cai mais de $97 \%$ em cinco anos. In: Terras de Direitos, 14 maio 2018. Disponível em: <https://terradedireitos.org.br/noticias/ noticias/orcamento-para-titulacao-de-territorios-quilombolas-caimais-de-97-em-cinco-anos/22824>. Acesso em: 10 mar. 2019.

SILVA, Tatiana D. Texto para Discussão 1712: O Estatuto da Igualdade Racial. Rio de Janeiro: IPEA, 2012. Disponível em: <http://www.ipea. gov.br/agencia/images/ stories/PDFs/TDs/td_1712.pdf>. Acesso em: 20 ago. 2018.

\section{TERRA DE DIREITOS. Denúncia à Comissão Interamericana de} Direitos Humanos. Disponível em: <https://terradedireitos.org.br/ uploads/arquivos/denuncia-CIDH.pdf>. Acesso em: 22 set. 2018.

. MPF investiga políticas públicas para demarcação de terras de quilombolas. Disponível em: <https://terradedireitos.org.br/noticias/ noticias/mpf-investiga-politicas-publicas-para-demarcacao-de-terrasde-quilombolas/2296>. Acesso em: 13 fev. 2011.

VERDUM, Ricardo. Nota Técnica 168: Orçamento Quilombola 20082010 e a maquiagem na titulação. Disponível em: <http://www.inesc. org.br/biblioteca/publicacoes/notas-tecnicas/NT.\%20168\%20-\%20 Orcamento\%20Quilombola.pdf>. Acesso em: 27 de julho 2010. 